\title{
Artikel
}

\section{Erfrecht in de onderwereld (deel 1)}

\author{
Mr. L.A.G.M. van der Geld*
}

\section{Inleiding}

De liquidaties in Amsterdam lijken elkaar steeds sneller op te volgen. ${ }^{1}$ Hiermee wordt de vraag actueel naar de gevolgen van het verkriigen van een nalatenschap waarvan de goederen geheel of gedeeltelijk een relatie met een misdrijf hebben. Het erfrecht ontmoet dan het strafrecht. In het eerste deel worden de voor het erfrecht relevante bepalingen uit het strafrecht verkend. In deel 2 wordt onder meer ingegaan op socialezekerheidsfraude en de navordering van de fiscus.

\section{Ontneming wederrechtelijk verkregen voordeel}

Als er een strafrechtelijke procedure loopt tegen erflater, dan vervalt deze met zijn overlijden (art. 69 van het Wetboek van Strafrecht, $\mathrm{Sr}$ ). Na het overlijden van een verdachte kan de rechter op grond van artikel $36 \mathrm{~b} \mathrm{Sr}$ op vordering van het Openbaar Ministerie (OM) wel een beschikking uitspreken ter onttrekking van gemeengevaarlijke voorwerpen (zoals bijvoorbeeld vuurwapens) aan het verkeer. ${ }^{2}$ Hiermee verkrijgt het $\mathrm{OM}$ een vordering op de erfgenamen tot afgifte van de gemeengevaarlijke voorwerpen.

Gaat het om financiële opbrengsten uit criminele activiteiten, dan heeft het OM tijdens leven van de verdachte/veroordeelde verschillende mogelijkheden om die opbrengsten 'af te pakken'. In de Aanwijzing afpakken, ${ }^{3}$ die vanaf 1 januari 2014 geldt, staan de verschillende afpakmogelijkheden vermeld. Een van de afpakmogelijkheden is de ontneming van wederrechtelijk verkregen voordeel van artikel 36e $\mathrm{Sr}$. Het wederrechtelijk verkregen voordeel bestaat onder meer uit de waarde waarmee het vermogen van de betrokken persoon als gevolg van het strafbare feit is toegenomen. Kan het OM ook na overlijden van de verdachte/veroordeelde erflater een vordering instellen ex artikel 36e Sr? Deze vraag moet ontkennend worden beantwoord. Uit de memorie van toelichting op de Wet strekkende tot verruiming van de mogelijkheden tot ontneming van wederrechtelijk verkregen voordeel ${ }^{4}$ en een arrest van de Hoge Raad uit $2008^{5}$ blijkt dat door het overlijden van de verdachte persoon niet alleen het recht tot het instellen of voortzetten van een strafvervolging tegen hem vervalt, maar ook het recht tot het aanvangen of voortzetten van een procedure tot ontneming van wederrechtelijk verkregen voordeel. Als de ontnemingsbeslissing onherroepelijk is, dan vervalt de vordering die uit deze
* Mr. L.A.G.M. van der Geld is juridisch directeur Netwerk Notarissen, kandidaat-notaris en docent aan het Centrum voor Notarieel Recht van de Radboud Universiteit Nijmegen.

1. 'Liquidaties in Amsterdam, het gaat maar door', <www.rtlnieuws.nl> 11 februari 2015: 'Eind 2012 escaleerde de strijd in de Amsterdamse onderwereld. Een reeks incidenten was het gevolg, de meeste met dodelijke afloop.' In 2015 werden in de eerste zes weken van het jaar in Amsterdam zes mensen geliquideerd. In een aantal van die liquidaties gaat het mogelijk om persoonsverwisselingen.
2. HR 6 november 2001, ECLI:NL:HR:2001:AD4430, NJ 2002/173: uit dit arrest blijkt dat als tijdens leven reeds een vordering was ingesteld, deze opnieuw na het overlijden moet worden ingesteld. In de casus van het arrest betrof het gemeengevaarlijke voorwerp als bedoeld in art. 36b Sr een hond, vuilnisbakkenras, kleur: bruin, genaamd 'Bobby'.

3. Stcrt. 23 december 2013, 35782

4. Kamerstukken II 1989 /90, 21504, 3, p. 9.

5. HR 18 maart 2008, ECLI:NL:HR:2008:BC2339, NJ 2008/181. 
beslissing voortvloeit niet. ${ }^{6}$ De vordering van de Staat moet mijns inziens worden beschouwd als een schuld van de nalatenschap in de zin van artikel 4:7 lid 1 onder a van het Burgerlijk Wetboek (BW).

\section{Witwassen door aanvaarding nalatenschap}

Als het niet mogelijk is om ex artikel 36e Sr het wederrechtelijk verkregen voordeel te ontnemen omdat de verdachte overleden is voordat de vordering is ingesteld of de ontnemingsbeslissing onherroepelijk is, kan dan nog worden voorkomen dat de misdaad van erflater de erfgenamen loont? Het OM kan tegen de erfgenamen een 'zaak maken' op basis van de strafbaarheidsstelling van witwassen alsmede de verbeurdverklaring/ontneming van de opbrengst van het witwassen.

Op grond van artikel 420bis lid 1 onder b Sr is witwassen strafbaar. Het 'voorwerp' als vermeld in dit lid moet van een misdrijf afkomstig zijn en de verdachte moet het 'voorwerp voorhanden hebben'. Verder moet de verdachte weten dat 'het voorwerp - onmiddellijk of middellijk - afkomstig is uit enig misdrijf. Uit lid 2 volgt dat onder voorwerpen worden verstaan 'alle zaken en alle vermogensrechten'. Het 'voorhanden hebben' betekent het voorwerp feitelijk tot beschikking hebben. Uit de wetsgeschiedenis volgt dat chartaal geld een voorwerp is in de zin van artikel 420bis Sr.

Als erfgenamen een nalatenschap, waarvan de goederen geheel of gedeeltelijk afkomstig zijn uit een misdrijf, zuiver dan wel beneficiair aanvaarden, zijn erfgenamen op grond van de wettekst van artikel 420bis Sr 'automatisch' schuldig aan witwassen. Dit blijkt uit het arrest van de Hoge Raad van 5 september $2006 .{ }^{7}$ In de casus van het arrest zijn de twee minderjarige kinderen van erflater erfgenamen. Het door erflater nagelaten vermogen staat op de derdengeldenrekening van een notaris. Volgens het OM heeft het vermogen van erflater een criminele herkomst; reden waarom het OM strafvorderlijk beslag onder de notaris op de derdengeldenrekening heeft doen leggen. Het OM stelt dat de wettelijke vertegenwoordigsters zich door de aanvaarding van de nalatenschap schuldig hebben gemaakt aan witwassen in de zin van artikel 420bis Sr. Volgens de Hoge Raad moet in het licht van de wetsgeschiedenis ${ }^{8}$ artikel 420bis $\mathrm{Sr}$ aldus worden uitgelegd dat zuivere dan wel beneficiaire aanvaarding van een nalatenschap tot gevolg heeft dat de erfgenaam de tot de nalatenschap behorende goederen voorhanden heeft in de zin van deze wetsbepaling. Daarnaast moet worden beoordeeld of de erfgenaam weet dat de goederen onmiddellijk of middellijk afkom-

6. In art. $75 \mathrm{Sr}$ is het adagium 'het strafrecht richt zich tot de levenden, niet tot de doden' neergelegd. Dit artikel maakt evenwel een uitzondering voor de maatregel tot ontneming van wederrechtelijk verkregen voordeel op de regel dat door het overlijden van de veroordeelde het recht tot uitvoering van de straf of maatregel vervalt.

7. HR 5 september 2006, ECLI:NL:HR:2006:AU6712, NJ 2006/612.

8. Kamerstukken I 2001/02, 27159, 33a, p. 5-6. stig zijn uit enig misdrijf. Als aan deze vereisten is voldaan, is op grond van een redelijke wetsuitleg niet onder alle omstandigheden sprake van witwassen in de zin van artikel 420bis Sr. De Hoge Raad noemt als uitzonderingen:

- De erfgenaam weet bij aanvaarding dat de nalatenschap één of meer goederen bevat die afkomstig zijn uit enig misdrijf, maar heeft niet het oogmerk de feitelijke zeggenschap daarover te gaan uitoefenen. Uit het, al dan niet via tussenkomst van de notaris, onverwijld melden aan de politie of officier van justitie dat de nalatenschap zulke goederen omvat, kan het ontbreken van het oogmerk feitelijke zeggenschap daarover uit te oefenen, worden afgeleid.

- De wetenschap over de herkomst van de nalatenschap is eerst opgekomen na de aanvaarding van de nalatenschap en de erfgenaam heeft daarna insgelijks gehandeld.

Uit dit arrest kan worden afgeleid dat (ook het door de aanvaardingsfictie van art. 4:192 BW) zuiver aanvaarden van de nalatenschap nog geen desastreuze strafrechtelijke gevolgen hoeft te hebben. Het is van belang hoe de erfgenaam omgaat met de wetenschap: heeft de erfgenaam het oogmerk feitelijke zeggenschap over de goederen van de nalatenschap uit te oefenen die afkomstig zijn uit enig misdrijf? Als de erfgenaam niet het oogmerk heeft feitelijke zeggenschap over die goederen te willen uitoefenen en daar ook naar handelt, dan hoeft er geen sprake te zijn van witwassen. Door onverwijld politie en justitie in te lichten en de goederen afkomstig uit enig misdrijf aan de Staat af te dragen laat de erfgenaam zien dat hij niet het oogmerk heeft feitelijke zeggenschap over die goederen te willen uitoefenen. ${ }^{9}$

Annotator Borgers ${ }^{10}$ betwijfelt of het overboeken van het geld afkomstig uit een misdrijf naar een goed doel voldoende is. Hij gaat ervan uit dat een erfgenaam om een veroordeling wegens witwassen te voorkomen altijd het 'misdaadgeld' aan de Staat moet overdragen. Uit de door de Hoge Raad in het arrest vermelde uitzondering lijkt mij inderdaad te moeten worden afgeleid dat het misdaadgeld direct naar de Staat moet. Dat het misdaadgeld in de tussentijd op de kwaliteitsrekening van de notaris wordt 'geparkeerd', is mijns inziens geen probleem. Borgers gaat daar overigens in zijn noot niet op in. Als een erfgenaam eerst later wetenschap krijgt van het misdaadgeld en inmiddels is met dit geld een woning verkregen, moet dan de woning aan de Staat worden overgedragen? Volgens Borgers is dat niet zonder meer redelijk.

Op 4 oktober 2012 zijn de moeder (enig erfgenaam) van de vermoorde Michael Vane en advocaat Arthur T. veroordeeld voor onder meer het witwassen van 'misdaad-
9. Naar verluidt zou de partner van de geliquideerde topcrimineel Mieremet de goederen van 'criminele afkomst' aan de Staat hebben afgestaan om vervolging wegens witwassen te voorkomen. Volgens berichten in de media zou Sonja Holleeder, partner van Heinekenontvoerder Cor van Hout, hetzelfde hebben gedaan.

10. Noot van M.J. Borgers bij NJ 2006/612. 
geld' uit de nalatenschap van Vane. ${ }^{11}$ Als de moeder van Vane verneemt dat haar zoon een aanzienlijk vermogen had, neemt zij contact op met advocaat T. om het nagelaten vermogen te achterhalen. Als beloning voor zijn werkzaamheden komen zij overeen dat T. 10 procent van het te achterhalen vermogen ontvangt. Volgens het $\mathrm{OM}$ is het vermogen van Vane afkomstig uit een misdrijf: hij deed onder meer aanzienlijke stortingen in contanten op zijn rekening. Daarnaast kon uit de zeer gewelddadige manier waarop Vane om het leven is gebracht, worden afgeleid dat hij criminele activiteiten ontplooide. Zowel de moeder van Vane als T. had er volgens het $\mathrm{OM}$ wetenschap van dat de nalatenschap van Vane geheel of gedeeltelijk uit misdaadgeld bestond of in ieder geval wetenschap daarvan kunnen hebben. De rechter veroordeelt zowel de moeder van Vane als $T$. wegens witwassen omdat zij het misdaadgeld aan het zicht van de justitiële autoriteiten onttrokken en het een schijnbaar legale herkomst verschaften door onder meer het geld door te sluizen naar een bankrekening in Zwitserland. Dat T. de feiten in zijn hoedanigheid van advocaat heeft gepleegd, wordt door de rechtbank in het bijzonder meegewogen. Een advocaat moet de belangen van zijn cliënt behartigen, waarbij hij de grenzen van de wet in acht neemt. De samenleving moet er volgens de rechter op kunnen vertrouwen dat een advocaat die verzocht wordt van dienst te zijn bij het plegen van strafbare feiten dat verzoek afwijst. T. heeft door zijn handelen dat vertrouwen beschadigd en met zijn handelen eraan bijgedragen dat de onder- en bovenwereld verweven raken.

\section{Vereffening 'criminele nalatenschap'}

Op grond van artikel 4:203 lid 1 onder b BW kan het OM de rechter verzoeken een derde-vereffenaar te benoemen, onder meer als de vereffenaar ongeschikt is voor de vervulling van de vereffeningsverplichtingen. Uit de jurisprudentie blijkt dat het OM van deze bevoegdheid gebruik maakt als sprake is van een nalatenschap die goederen omvat die verkregen zijn uit een misdrijf.

In de nalatenschap van Aran de Jong ${ }^{12}$ verzochten het $\mathrm{OM}$ en de Ontvanger van de Belastingdienst een derde als vereffenaar te benoemen. ${ }^{13}$ In de nalatenschap van deze erflater zijn de echtgenote en de kinderen erfgenamen en is de schoonvader van erflater executeur. De erfgenamen hebben de nalatenschap beneficiair aanvaard en zijn op grond van artikel 4:195 BW de vereffe-

11. Rb. Amsterdam 4 oktober 2012, ECLI:NL:RBAMS:2012:BX9129.

12. Aran de Jong werd op 17 november 2012 doodgeschoten voor zijn woning. Blijkens een vonnis van 7 maart 2013 werd hij beschouwd als leider van een criminele organisatie, die grootschalige transporten van hennep uitvoerde en gelden witwaste. Eerder werd hij veroordeeld ter zake van drugshandel, valsheid in geschrifte, wapenbezit, verkeersdelicten en openlijke geweldpleging.

13. Rb. Oost-Brabant 20 juni 2013, ECLI:NL:RBOBR:2013:CA3940. naar van de nalatenschap. Het $\mathrm{OM}$ en de Belastingdienst verzoeken de rechter een derde tot vereffenaar te benoemen omdat het $\mathrm{OM}$ wederrechtelijk verkregen voordeel wil ontnemen dat is becijferd op $€ 41$ miljoen. Door de Belastingdienst is een navorderingsaanslag aan de erfgenamen opgelegd van ruim $€ 25.000$. Het gaat volgens het $\mathrm{OM}$ en de Belastingdienst om een zeer ingewikkelde nalatenschap, waardoor de erfgenamen ongeschikt zijn om als vereffenaar op te treden. ${ }^{14} \mathrm{De}$ erfgenamen zien geen grond voor de benoeming van een externe vereffenaar en voeren onder meer aan dat de vordering van het $\mathrm{OM}$ nog niet door de rechter is getoetst. De executeur heeft bovendien nog niet de 'ruimschootsverklaring' van artikel 4:202 lid 1 onder a BW kunnen afleggen omdat de executeur nog bezig is zicht te krijgen op de omvang van de nalatenschap.

Volgens de rechter worden met de benoeming van een externe vereffenaar geen rechten van erfgenamen dan wel schuldeisers aangetast of verkort. De maatregel houdt uitsluitend in dat de nalatenschap op formele en de juiste manier wordt afgewikkeld. Daar kan, volgens de rechter, niemand bezwaar tegen hebben. De rechter benoemt een derde (een advocaat) tot vereffenaar, mede omdat er in deze casus sprake is van een gecompliceerde nalatenschap waarin de erfgenamen 'situationeel ongeschikt' zijn om als vereffenaar (en executeur) op te treden. Immers, als de erfgenamen bepaalde vermogensbestanddelen antreffen, moeten zij daarover contact opnemen met justitie en is de kans 'niet denkbeeldig dat [justitie c.s.] daarmee een jegens [de erfgenamen] meer welwillende houding zullen aannemen dan objectief gezien gerechtvaardigd zou zijn'. Daarbij komt dat de echtgenote nu haar best moet doen om niet de schijn te wekken dat zij gelden aan de nalatenschap onttrekt. Een externe vereffenaar kan zonder die verdachtmaking schulden van de nalatenschap voldoen.

Recent deed de rechter opnieuw een uitspraak over een verzoek van het $\mathrm{OM}$ een derde tot vereffenaar te benoemen. ${ }^{15}$ Volgens het OM zijn de erfgenamen als vereffenaars situationeel ongeschikt om als vereffenaars op te treden en is de notaris aan wie de erfgenamen volmacht hebben verleend eveneens ongeschikt omdat zij 'te nauw betrokken is bij de familie'. Het onderzoek naar het vermogen van erflater, die werd verdacht van drugshandel en witwassen, is nog in volle gang en is een van de redenen die het $\mathrm{OM}$ anvoert voor het benoemen van een derde tot vereffenaar. Er is, zo stelt het OM, een sterke behoefte aan een 'krachtige en deskundige vereffenaar die de belangen van de schuldeisers en de erfgenamen weegt $(\ldots)$ '. De erfgenamen voeren tegen het verzoek aan dat zij een notaris als deskundige voor de vereffening hebben ingeschakeld. De notaris betrekt het OM

14. Volgens het $\mathrm{OM}$ en de Belastingdienst hebben de echtgenote en haar vader (schoonvader/executeur van erflater) zich schuldig gemaakt aan strafbare feiten als het witwassen van gelden en het verhullen van strafbare feiten. Deze morele ongeschiktheid wordt door de rechter bij de beoordeling van het verzoek buiten beschouwing gelaten omdat zij zijn vrijgesproken en nog niet bekend is wat het oordeel in hoger beroep is.

15. Rb. Midden-Nederland 30 januari 2015, ECLI:NL:RBMNE:2015:463. 
bij de afwikkeling van de nalatenschap. En: anders dan het OM stelt, is het intrekken van de volmacht aan de notaris niet meer aan de orde omdat aan de notaris inmiddels een volgens de erfgenamen 'privatieve volmacht' is gegeven.

Volgens de rechter zijn er onvoldoende concrete aanwijzingen voor de stelling dat de erfgenamen ongeschikt zijn als vereffenaars van de nalatenschap. Het $\mathrm{OM}$ is nog geen schuldeiser van de nalatenschap omdat er nog geen ontnemingsvordering is ingediend. In verband met die eventuele ontnemingsvordering is door de notaris aan het OM toegezegd dat de gelden uit de nalatenschap op zijn kwaliteitsrekening worden gehouden in afwachting van duidelijkheid over de vraag of die afkomstig zijn uit een misdrijf.

\section{Tot slot (deel 1)}

Als tot een nalatenschap financiële opbrengsten behoren uit criminele activiteiten van een erflater, dan wordt het handelen van de erfgenamen op een goudschaaltje gewogen. Het OM kan vanwege een rechterlijke ontnemingsbeslissing die tijdens het leven van erflater is verkregen, een vordering hebben op de nalatenschap. Er is dan sprake van een schuld van de nalatenschap van erflater in de zin van artikel 4:7 lid 1 onder a BW. De erfgenamen doen er dan verstandig aan deze schuld spoedig te voldoen. In verband met mogelijke vervolging vanwege witwassen is het voor erfgenamen die de nalatenschap zuiver dan wel beneficiair hebben aanvaard en wetenschap hebben dan wel kunnen hebben dat een deel of de gehele nalatenschap afkomstig is uit een misdrijf, van belang spoedig de betreffende goederen over te dragen aan de Staat. De erfgenamen kunnen tevens worden geconfronteerd met het verzoek van het $\mathrm{OM}$ c.s. aan de rechter een derde tot vereffenaar te benoemen. Het OM zal in verband met artikel 4:203 lid 1 onder b BW aanvoeren dat de erfgenamen 'ongeschikt' zijn om de nalatenschap te vereffenen.

Voor een notaris of advocaat die de erfgenamen bijstaat in de afwikkeling/vereffening van de nalatenschap is het belangrijk alert te zijn op eventuele misdaadgelden in de nalatenschap. Niet alleen in verband met de advisering aan de erfgenamen, maar ook om zelf niet betrokken te raken dan wel mee te werken aan de verwevenheid van de onder- en bovenwereld. 